Dicle Tıp Dergisi / Dicle Med J (2019) 46 (3) : 559 - 565

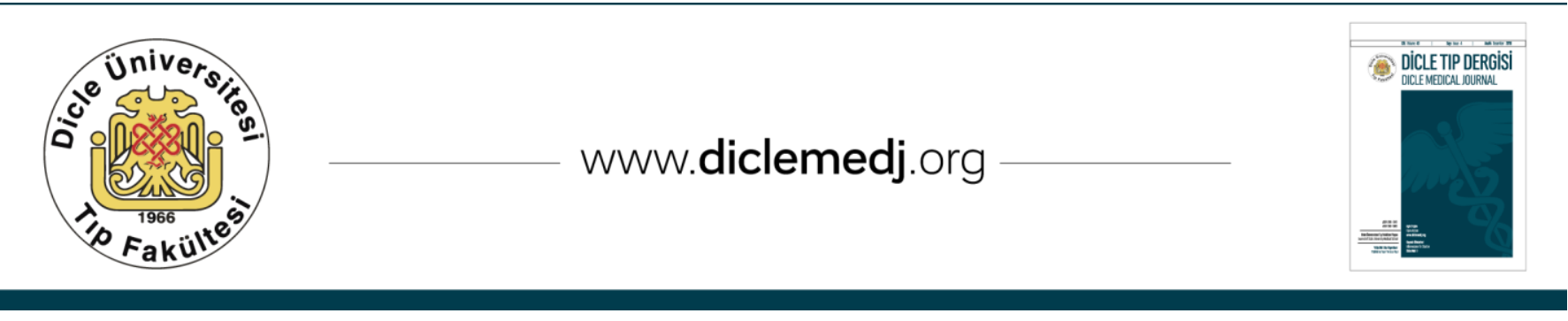

Özgün Araștırma / Original Article

\title{
Bir Üniversite Hastanesi Çocuk Psikiyatrisi Polikliniğinde Değerlendirilen Suça Sürüklenen Çocuklar
}

\author{
Tuğba Yüksel ${ }^{1}$ \\ 1 Dicle Üniversitesi Çocukve Ergen Ruh Sağlı̆̆ Anabilim Dalı / Diyarbakır, Türkiye ORCID: 0000-0001-5611-2739 \\ Geliş: 24.07.2019; Revizyon: 30.07.2019; Kabul Tarihi: 26.08.2019
}

\section{Öz}

Amaç: Ülkemizde ve dünyada ergenlerle ilgili adli davalar gün geçtikçe artmakta, çocuk psikiyatristleri ve adli tıp hekimleri adli ve mesleki anlamda daha çok bilgi ve tecrübe gereksinimi duymaktadır. Erkek çocuk ve ergenlerde, saldırgan davranışlar ve suça sürüklenmenin daha sık olduğu farklı çalışmalarda gösterilmiştir. Çalışmamızın amacı; adli makamlarca Türk Ceza Kanunu (TCK) 31 ve 32 maddeleri gereğince çocuk psikiyatrisi polikliniğine getirilen çocukların psikiyatrik muayenelerini yaparak tanı, sosyodemografik veriler, suçun niteliği ve suça iten riskleri belirlemektir. Ek olarak hazırlanan raporların incelenmesi de amaçlanmaktadır.

Yöntemler: Araştırma, hastanemiz etik kurulundan onay alındıktan sonra, Haziran 2017- Kasım 2018 tarihleri arasında Çocuk psikiyatrisi polikliniğine adli psikiyatrik muayene amacıyla getirilen, işlendiği iddia edilen suçun hukuki anlam ve sonuçlarını algılama ve davranışlarını yönlendirme yeteneğinin gelişip gelişmediği veya akıl hastalığı sorulan suça sürüklenen 107 çocuğun geriye dönük dosyaları incelenerek düzenlenmiştir.

Bulgular: Çalışmaya alınan çocuklarda erkek cinsiyet, okulu bırakma oranları, madde kullanımı, dikkat eksikliği ve hiperaktivite bozukluğu (DEHB), davranış bozukluğu varlığının ve sosyoekonomik düzeyin düşüklügününyüksek olduğu tespit edildi. En sık işlenen suç hırsızlıktı (\% 37,3), bunları sırasıyla terör (\%25,2), yaralama (\%17,8), cinsel istismar (\%15) ve uyuşturucu $(\% 4,7)$ suçları izliyordu. 107 çocuktan 27'sinde $(\% 31,8)$ işledikleri fiilin hukuki anlam ve sonuçlarını algılama veya bu fille ilgili olarak davranışlarını yönlendirme yeteneğinin yeterince gelişmediği, 20 $(\% 23,5)$ çocukta işledikleri fiilin hukuki anlam ve sonuçlarını algıladığı bu fiille ilgili olarak davranıșlarını yönlendirme yeteneğinin geliştiği, $38(\% 44,7)$ çocukta işledikleri iddia edilen fiilin hukuki anlam ve sonuçlarını algıladığı ancak davranışlarını yönlendirme yeteneğinin yeterince gelişmediği tıbbi kanaatine varıldı. 6 çocukta akıl hastalığı mevcudiyeti nedeniyle TCK 32. madde gereğince fiilin hukuki anlam ve sonuçlarını algılama ve davranışlarını yönlendirme yeteneğinin yeterince gelişmediği, yine 6 çocukta ise akıl hastalığının mevcut olmadığı tıbbi kanaatine varıld. 
Sonuç: Suça sürüklenen çocukların genel özelliklerinin ve risk faktörlerinin bilinmesi, sosyal, kültürel ve ekonomik ihtiyaçlarının karşılanması sonuç olarak bu davranışların önlenmesi ve gerekli tedbirlerin alınmasına katkıda bulunabilmesi açısından önem arz etmektedir.

Anahtar kelimeler: suça sürüklenen çocuklar, sosyodemografik özellikler, psikiyatrik değerlendirme, risk faktörleri, suç davranışları.

\title{
Children Drawn to Crime Assessed in Children's Psychiatry Outpatient Clinic of a University Hospital
}

\begin{abstract}
Objective: Judicial cases related to adolescents in Turkey and the world are increasing day by day, and child psychiatrists and forensic physicians need more knowledge and experience in forensic and professional terms. It has been shown in different studies that aggressive behavior and crime is more frequent in boys and adolescents. The aim of this study is to determine the diagnosis, sociodemographic data, the nature of the crime and the risks that push against the crime by making the psychiatric examinations of the children brought to the child psychiatry outpatient clinic according to Turkish Criminal Law (TCL) 31 and 32 by the judicial authorities. It is also aimed to examine the reports prepared in addition.

Method: The study was designed to examine the retrospective files of 107 children who were admitted to Child and Adolescent Mental Health and Diseases Outpatient Clinic between 2017-June and November 2018 under the scope of TCK 31 and 32 for forensic psychiatric examination after the approval of the ethics committee of our hospital.

Results: Male gender, dropout rates of school, substance use, attention deficit and hyperactivity disorder (ADHD), presence of behavior disorder and low socioeconomic status were found in the children included in the study. The most common crime was theft (37.3\%), followed by terror (25.2\%), wounding (17.8\%), sexual abuse (15\%) and drug (4.7\%) crimes respectively. It has been determined that the ability to perceive the legal meaning and the consequences of the crime, which is claimed to be committed and to direct the behaviors related to this act, has not developed sufficiently in $77 \%$ of the cases.

Conclusion: Knowing the general characteristics and risk factors of the children who are involved in crime and meeting their social, cultural and economic needs are important in order to prevent these behaviors and contribute to taking necessary measures.
\end{abstract}

Keywords: Children dragged into crime, sociodemographic characteristics, psychiatric assessment, risk factors, criminal behavior.

\section{GİRIŞ}

Ergenler, ciddi suç davranışlarının önemli bir kısmını oluşturur ve ergen suçluluğu, çoğu modern toplumlar için zorlayıcı bir faktördür1. Ülkemizde ve dünyada ergenlerle ilgili adli davalar gün geçtikçe artmakta, çocuk psikiyatristleri ve adli tıp hekimleri adli ve mesleki anlamda daha çok bilgi ve tecrübe gereksinimi duymaktadır. Kanunlarda suç sayılan fiili işlediği iddiasıyla hakkında soruşturma ya da kovuşturma yapılan veya işlediği fiil sonucunda hakkında güvenlik tedbiri alınmasına karar verilen şahıslar suça sürüklenen çocuklar olarak adlandırılmaktadır². Türk hukuk sistemine göre 'suçlu çocuk yoktur, suça sürüklenen çocuk vardır' ilkesi benimsenmiş, çocukların suç işlerken irade dışı faktörlerin etkisi olduğu düşünülmüştür ${ }^{3}$. Bir çalışmada suça karışmanın ülkemizde 14-15 yaş grubu ergen popülasyonda daha fazla olduğu, en slk karşılaşılan suçun ise hırsızlık olduğu bildirilmiştir ${ }^{4}$. Çocukluk çağındaki yıkıcı davranışlar, daha sonraki antisosyal ve cezai davranışlarla ilişkilendirilmiştir. Ylkıcı davranışı olan 92 çocukla yapılan bir çalışmada yıkıcı davranışın şiddeti emosyonel bozukluğun yoğunluğunu öngörmüştür ${ }^{5}$.

Suça sürüklenen çocukların adli işlemleri sırasında çocuk psikiyatristlerine en sık sorulan 
sorulardan bir tanesi çocuğun işlediği iddia edilen suçun hukuki anlam ve sonuçlarını algılayıp-algılamadığı ve davranışlarını yönlendirme yeteneğinin gelişip-gelişmediği hakkında görüş istenmesidir. Türk Ceza Kanunun (TCK)'nın 31/1 maddesi gereğince fiili işlediği sırada 12 yaşını doldurmamış olan çocukların ceza sorumluluğu yoktur. TCK'nın 31/2 maddesi gereğince fiili işlediği sırada 12 yaşını doldurmuş olup da 15 yaşını doldurmamış olanların işlediği fiilin hukuki anlam ve sonuçlarını algılayamaması veya davranışlarını yönlendirme yeteneğinin yeterince gelişmemiş olması halinde ceza sorumluluğu yoktur.

Adli psikiyatrik muayene sırasında çocuğun, biyopsikososyal gelişimi göz önüne alınarak fiilin kanunla belirlenen bir suç olduğunu algılama ve davranışlarını yönlendirme yeteneğinin gelişip-gelişmediği ${ }^{6}$ çocuğun içinde büyüdügü çevre ile birlikte, sosyal, zihinsel, fiziksel, ahlaki ve ruhsal gelişimleri beraber değerlendirilir. Yani çocukta herhangi bir psikiyatrik bozukluğun bulunmaması ceza sorumluluğunun olduğunun kesin bir göstergesi değildir ${ }^{7}$.

Araştırmalar, çocuklarda cezai suç işlemenin statik ve dinamik risk faktörleri ile ilişkili olduğunu göstermiştir. Statik risk faktörleri değiştirilemezken, dinamik risk faktörleri müdahaleden etkilenebilir ${ }^{8}$.

Çalışmamızın amacı; adli makamlarca TCK 31 ve TCK 32 maddeleri gereğince çocuk psikiyatrisi polikliniğine getirilen çocukların psikiyatrik muayenelerini yaparak psikiyatrik tanı, sosyodemografik veriler, suçun niteliği ve suça iten riskleri belirlemektir. Ek olarak hazırlanan raporların incelenmesi de amaçlanmaktadır. $\mathrm{Bu}$ çocukların genel özelliklerinin ve risk faktörlerinin bilinmesi, sosyal, kültürel ve ekonomik ihtiyaçlarının karşılanması sonuç olarak bu davranışların önlenmesi ve gerekli tedbirlerin alınmasına katkıda bulunabilir9.

\section{YÖNTEMLER}

Araştırmamız, Dicle Üniversitesi Tıp Fakültesi etik kurulu tarafından (Tarih:21.01.2019 No: 73)onay alınarak, Haziran 2017- Kasım 2018 tarihleri arasında Dicle Üniversitesi Çocuk ve Ergen Ruh Sağlığı ve Hastalıkları Polikliniğine adli psikiyatrik muayene amaciyla getirilen ve TCK 31/2 ve 32 kapsamında değerlendirilen 107 çocuğun geriye dönük dosyaları incelenerek düzenlenmiştir. Ayrıntılı anamnezi alınan ve psikiyatrik muayenesi yapılan çocuklara klinisyen tarafından sosyodemografik veri formu doldurulmuştur.

\section{Sosyodemografik Veri Formu}

Çocuk ve Ergen Ruh Sağlığı ve Hastalıkları Polikliniğine getirilen her çocuk için rutin doldurulan, yarı yapılandırılmış bir görüşme formudur. Olgulara ait yaş, cinsiyet, eğitim durumu, anne babalarına ait yaş, eğitim durumu, meslek, akraba olup olmadıkları, kardeş sayısı, olgunun kaçıncı çocuk olduğu, herhangi bir tıbbi hastalık öyküsü, ilaç kullanımı, ameliyat olup olmadığını içermektedir.

\section{Ístatistiksel Analiz}

Araștırmada elde edilen veriler Statistical Package for the Social Sciences (SPSS) 17.0 programina girilerek istatistiksel değerlendirmeleri yapılmıştır. Gruplar arasında bazı sosyodemografik özellikler açısından karşılaştırmalar yapılırken ki kare testi kullanılmıştır.

Olguların işlemiş oldukları iddia edilen suç tipine göre yaş, anne-baba yaşı, kardeş sayısı, akrabalık, madde kullanımı, suç, tanı açısından değerlendirilmeler yapılırken öncelikle Kolmogorov Smirnov testi uygulanmış, normal dağılıma uyan ölçümsel verilerin karşılaştırılmasında Varyans Analizi (ANOVA) testi uygulanmıştır. Normal dağılıma uymayan ölçümsel veriler Kruskall Wallis Varyans Analizi ile gruplar arasında karşılaştırılmıştır. 


\section{BULGULAR}

Çalışmaya alınan 107 çocuğun yaş ortalaması $14,2 \pm 1,2$ idi. Olguların 103'ü erkek (\%96,3), 4'ü $(\% 3,7)$ kızdı. Çocuklardan 47'si Diyarbakır ilçelerden, 6 tanesi çevre illerden geliyordu. Suça sürüklenen çocukların kardeş sayısı ortalaması 5,6'ydı. 53(\%49,5) çocukta en az bir tane psikiyatrik hastalık mevcuttu. Ruhsal Bozuklukların Tanısal ve Sayımsal Elkitabı (DSM-5) tanı ölçütlerine göre 13 kişi hafif-orta zeka geriliği, 24 kişi Dikkat Eksikliği ve Hiperaktivite Bozukluğu (DEHB), 8 kişi davranım bozukluğu ve 7 kişi madde kullanım bozukluğu tanısı aldılar.

Çocukların sadece 37 (\%34,6)'sı okula devam ediyordu. Geri kalanı çeşitli nedenlerle okulu bırakmıştı. 30 (\%28) çocuğun daha önce suç öyküsü, $24 \quad(\% 22,4)$ çocuğun ise madde kullanım öyküsü mevcuttu. $24(\% 22,4)$ çocuk; hal, firın, inşaat, internet kafe gibi yerlerde çalışıyordu. $10(\% 10,7)$ 'u daha önce cezaevinde kalmıştı. (Tablo 1)

Tablo 1: Suça sürüklenen çocukların sosyodemografik özellikleri.

\begin{tabular}{|l|l|}
\hline \multicolumn{2}{|l|}{ Sosyodemografik özellikler } \\
\hline Yaş (ort) & 14,2 \\
\hline Cinsiyet & $\begin{array}{l}\text { Erkek(\%96,3), } \\
\operatorname{Kız}(\% 3,7)\end{array}$ \\
\hline Kardeş sayısı(ort) & 5,6 \\
\hline En az bir psikiyatrik hastalık & $\% 49,5$ \\
\hline Okula devam & $\% 34,6$ \\
\hline Suç öyküsü & $\% 28$ \\
\hline Madde kullanım öyküsü & $\% 22,4$ \\
\hline Cezaevinde kalma & $\% 10,7$ \\
\hline Çocuk işçi & $\% 22,4$ \\
\hline
\end{tabular}

En sık işlenen suç hırsızlıktı $(\% 37,3)$, bunları sırasiyla terör $(\% 25,2)$, yaralama $(\% 17,8)$, cinsel istismar (\%15) ve uyuşturucu $(\% 4,7)$ suçları izliyordu (Tablo 2).
Tablo 2: Suça sürüklenen çocukların suç çeşitleri ve bunların oranları.

\begin{tabular}{|l|l|}
\hline Suçlar & \% \\
\hline hırsızlık & 37,3 \\
\hline terör & 25,2 \\
\hline yaralama & 17,8 \\
\hline cinsel istismar & 15 \\
\hline diğer & 4,7 \\
\hline
\end{tabular}

Yapılan psikiyatrik değerlendirmeler sonucunda 107 çocuktan 27'sinde $(\% 31,8)$ işledikleri fiilin hukuki anlam ve sonuçlarını algılama veya bu fiille ilgili olarak davranışlarını yönlendirme yeteneğinin yeterince gelişmediği, $20 \quad(\% 23,5)$ çocukta işledikleri fiilin hukuki anlam ve sonuçlarını algıladığı bu fiille ilgili olarak davranışlarını yönlendirme yeteneğinin geliștiği, $38(\% 44,7)$ çocukta işledikleri iddia edilen fiilin hukuki anlam ve sonuçlarını algıladığı ancak davranışlarını yönlendirme yeteneğinin yeterince gelişmediği tıbbi kanaatine varıldı. 6 çocukta akıl hastalığ mevcudiyeti nedeniyle TCK 32. madde gereğince fiilin hukuki anlam ve sonuçlarını algılama ve davranışlarını yönlendirme yeteneğinin yeterince gelişmediği, yine 6 çocukta ise akıl hastalığının mevcut olmadığı tıbbi kanaatine varıldı. Psikiyatrik tanı alan 7 kişiye tedavi başlanarak sağlık tedbiri kararı aldırılması talebinde bulunuldu.

\section{TARTIŞMA}

Suça sürüklenen çocuk ve ergenlerin nasıl yargılanacakları, bu bireyleri değerlendirirken neler yapılması gerektiği ve sosyal hayata tekrar nasıl dahil edilmeleri gerektiğini belirlemek, suça sürükleyen faktörleri tespit etmek ve yapılan davranışları önleyecek tedbirler almak önemlidir.

Biz de çalışmamızda suça sürüklenen çocukların sosyodemografik özellikleri, işlenmiş olduğu iddia edilen suç tipi, eşlik eden psikiyatrik tanılar ve verilen kararları retrospektif olarak inceledik. Çalışmaya alınan 
çocuklarda erkek cinsiyet, okulu bırakma oranları, madde kullanımı, dikkat eksikliği ve hiperaktivite bozukluğu (DEHB), davranış bozukluğu varlığının ve sosyoekonomik düzeyin düşüklügünün yüksek olduğu tespit edildi.

Şiddet ve suça eğilim davranışlarının ortaya çıkması biyolojik, sosyal, çevresel ve bireysel risk faktörlerinin bir sonucu olduğu ileri sürülmektedir. Erkeklerde suç ve şiddetin daha fazla olduğu, suç sırasında daha saldırgan oldukları gösterilmiş ${ }^{10-12}$ ve polikliniğimizde değerlendirilen suça sürüklenen çocukların da büyük bir kısmını $(\% 96,3)$ erkeklerin oluşturduğu dikkat çekmiştir.

Çalışmamızda olguların yaş ortalamaları 14,2 olup, literatürde en sık suça karışma yaşının 14-16 olduğu bilinmektedir. Yine suça sürüklenen çocukların yaklaşık üçte birinin okula gitmediği, kardeş sayısının fazla olduğu ve düşük sosyoekonomik düzeylerinin olduğu tespit edilmiştir. Yapılan çalışmalarda suç öyküsü olan çocukların alıcı ve ifade edici dil becerilerinin ve okuma-yazma becerilerinin suça karışmamış yaşıtlarından daha düşük olduğu gösterilmiştir ${ }^{13,14}$.

Çocukların suça sürüklenmesi multifaktöriyel etkenlere bağlanmıştır. Bireysel özelliklerin akran-aile ilişkileri, toplum özellikleri ve okul ortamı ile etkileşim sonucu ortaya çıktığı gösterilmiştir ${ }^{15}$. Çocukluk çağında öfke ve huzursuzluğun bulunması ${ }^{16}$,kişilere karşı acımasız duyguların varlığ ${ }^{17}$, düşük zeka seviyesi18, dikkat eksikliği ve hiperaktivite bozukluğu ve davranış bozukluğunun varlığ ${ }^{17}$, çocukluk çağında istismar ve ihmal ${ }^{19}$, bakım verenlerin sık sık değişmesi ve çocuğa karşı tutarsız disiplin yöntemleri kullanılması ${ }^{19}$, suç davranışı açısından risk etkenleridir.

Birçok çalışma, sabıka kaydı olan çocuk ve ergenlerin psikiyatrik bozukluk sıklığını araştırmış, suça sürüklenen çocukların \%5070'inin en az bir psikiyatrik bozukluğu olduğu bildirilmiştir ${ }^{20}$. Suça karışan gençlerin çoğunun, özellikle davranış bozuklukları, DEHB ve madde bağımlılığı gibi psikiyatrik bir bozukluğu olduğu, suçlu gençlerin \%1020 'sinde anksiyete ve depresif bozuklukların bulunduğu tespit edilmiştir.

Özellikle birden fazla bozukluğun varlığı, suç davranışının doğası ve ciddiyeti ile ergenin işlevsizliği arasında bir bağlantı olduğu gösterilmiştir ${ }^{21}$. Araştırmamızda da suça sürüklenen çocuklardan psikiyatrik tanı alanların $(\% 49,5)$ büyük bir kısmını $(\% 73,6)$; DEHB, davranım bozukluğu ve madde kullanım bozukluğu oluşturuyordu.

Ayrıca çocuğun okulu bırakma öyküsünün varlığı, okula gitme isteğinin az olması ${ }^{17}$, suça eğilimli arkadaşlarının bulunması ${ }^{21}$, sosyoekonomik düzeyin düşüklüğü ${ }^{22}$, ciddi anne-baba sorunlarının olması ${ }^{17}$, ailede suç öyküsü varlığı ve kötü koşullarda çocuğun büyütülmesi ${ }^{19}$ de çocuğun suça meyilini arttıran diğer risk etkenleridir. Araştırmamızda çocukların sadece \%34,6'sı okula devam ediyordu. Geri kalanı çeşitli nedenlerle okulu bırakmıştı. Çocukların \%28'inin daha önce suç öyküsü mevcuttu. Türkiye'de yapılan bir çalışmada çocukların \%41,9'unun okula düzenli gitmediği, \%26,6'sının anne-baba ile yaşamadığı, annelerin \%30,1'inin okumayazma bilmediği, babaların \%33,8'inin ilkokulu bitirdiği, \%38'inin ailesinin göçle geldiği, \%24,9'unun madde kullanımı olduğu belirlenmiştir ${ }^{24}$.

En sık işlenen suç hırsızlıktı $(\% 37,3)$, bunları sırasıyla terör suçları $(\% 25,2)$, kasten yaralama $(\% 17,8)$, cinsel istismar $(\% 15)$ ve uyuşturucu suçları $(\% 4,7)$ izliyordu. Terör suçlarının yazında belirtilen oranlardan ${ }^{11,25}$ daha yüksek olması bu bölgede yaşanan terör olayları, düşük sosyoekonomik düzey ve ailelerin çocukları denetleme düzeylerinin yetersizliği nedeniyle olabileceği düşünülmüştür ${ }^{26,27}$. Suç işleyen çocukların yeniden suça karışması beklediğimiz bir durumdur. Yaptığımız çalışmada bu 
çocukların \%28'inin daha önce farklı nedenlerle dava dosyası mevcuttu.

Yapılan psikiyatrik değerlendirmeler sonucunda TCK 31/2 kapsamında, 27 (\%31,8) çocuğun işledikleri fiilin hukuki anlam ve sonuçlarını algılama veya bu fille ilgili olarak davranışlarını yönlendirme yeteneğinin yeterince gelişmediği, $20(\% 23,5)$ 'sinin işledikleri fiilin hukuki anlam ve sonuçlarını algıladığı, bu fiille ilgili olarak davranışlarını yönlendirme yeteneğinin geliștiği, $38(\% 44,7)$ çocuğun ise işledikleri iddia edilen fiilin hukuki anlam ve sonuçlarını algıladığı ancak davranışlarını yönlendirme yeteneğinin yeterince gelişmediği tıbbi kanaatine varılmıştır. Nasıroğlu ve arkadaşlarının 2017 yılında yaptıkları bir araştırmada bu oranlar sırasıly \%58,1; \%22,6 ve \%19,4 idi (25). İki çalışmada da verilen kararların çocukların büyük bir kısmını yargılamanın uygun olmadığı şeklinde olması dikkat çekti.

6 çocukta akıl hastalığı mevcudiyeti nedeniyle TCK 32. madde gereğince fiilin hukuki anlam ve sonuçlarını algılama ve davranışlarını yönlendirme yeteneğinin yeterince gelişmediği, yine 6 çocukta ise akıl hastalığının mevcut olmadığı tıbbi kanaatine varıldı. Psikiyatrik tanı alan 7 kişiye tedavi başlanarak sağlık tedbiri kararı aldırılması talebinde bulunuldu.

Çocuk ve ergen suçları toplumun tüm bölümlerini ilgilendiren bir konudur ve bu suçları önlemeye çalışmak için risk faktörlerinin belirlenmesi önemlidir. Yapılan birçok çalışmada aile içi çatışma, aile bölünmesi, erkek olma, eğitime devam edememe ve çocuğun bireysel patolojileri, özellikle davranış bozuklukları ve DEHB'nin çocuk suçları için en önemli risk faktörleri olduğu tespit edilmiştir. Bu risklerin önceden tespit edilmesi, suçun müdahalelerle azaltılmasına katkı sağlayacaktır. Psikiyatrik hastalıkların erken tedavisi, okul ve aile içi streslere müdahale bunlardan birkaçıdır ${ }^{28}$. Çocukları suçtan uzak tutmak ve onları genel topluma yönlendirmek için, suç ve risk faktörleri arasındaki ilişki unutulmamalıdır.

Bir bireyin maruz kaldığı risk faktörlerinin sayısı arttıkça, bireyin şiddet içeren davranışlarda bulunma olasılığ Paylaşılan belirleyicilerin tanımlanması ve risk faktörlerinin belirlenmesini hedefleyen çok bileşenli müdahaleler, şiddeti önlemede, tek risk faktörlerini hedef alanlardan daha etkili olabilir ${ }^{19}$.

Çocukların genel özelliklerinin ve risk faktörlerinin bilinmesi, sosyal, kültürel ve ekonomik ihtiyaçlarının karşılanması sonuç olarak suça sürükleyici davranışların önlenmesi ve gerekli tedbirlerin alınmasına katkıda bulunabilir. Bu amaçla yapılacak daha fazla çalışmaya ihtiyaç vardır.

Çıkar Çatışması Beyanı: Bu çalışmada çıkar çatışması yoktur.

Finansal Destek: Bu çalışma herhangi bir fon tarafından desteklenmemiştir.

Declaration of Conflicting Interests: There is no conflict of interest in thisstudy.

Financial Disclosure: No financial support was received.

\section{KAYNAKLAR}

1. Plattner B, Giger J, Bachmann F, et all. Psychopathology and offense types in detained male juveniles. Psychiatry Res. 2012; 198: 285-90.

2. Çocuk Koruma Kanunu T.C. Resmi Gazete. 15 Temmuz 2005 sayl: 25876.

3. Bülbül S, Doğan S. Suça Sürüklenen Çocukların durumu ve Çözüm Önerileri. Çocuk Sağlığı ve Hastalıkları Dergisi. 2016; 59: 31-6.

4. Şişmanlar ŞG, Biçer Ü, Coşkun A. Adli Psikiyatri. Çocuk ve Ergen Psikiyatrisi Temel Kitabı. FÇ Çetin, A Coşkun, E İşeri ve ark. (Ed), Ankara, Çocuk ve Gençlik Ruh Sağllğı Derneği 2008; 770-81.

5. Hunnikin LM, Wells AE, Ash DP, et all. The nature and extent of emotion recognition and empathy impairments in children showing disruptive behaviour referred into a crime prevention programme. Eur Child Adolesc Psychiatry. 2019 
6. Köse S, Aslan Z, Başgül Ş.S, et all. Bir eğitim ve araştırma hastanesi çocuk psikiyatrisi polikliniğine yönlendirilen adli olgular. Anadolu Psikiyatri Derg. 2011; 12: 221-25

7. Kurtuluş A, Salman N, Günbet G, et all. Denizli İlinde 12-15 Yaș Arasındaki Suça Sürüklenen Çocukların Sosyodemografik Özellikleri. Pamukkale Tıp Dergisi. 2009; 2: 8-14

8. Mulder E, Brand E, Bullens R, et all. Risk Factors for Overall Recidivism and Severity of Recidivism in Serious Juvenile Offenders. Int J Offender Ther Comp Criminol. 2011; 55: 118-35.

9. Eyüboğlu M, Eyüboğlu D. Suça Sürüklenen Çocuklarda Psikiyatrik Bozukluklar, Sosyodemografik Özellikler ve Risk Faktörleri. Turkish J Clinical Psychiatry. 2018; 21: 7-14.

10. Tural-Hesapçığlu S, Yeşilova H. Muş'ta çocukergenlerde adli psikiyatrik değerlendirme: Suçu önlemeye bir bakış. Adli Tıp Dergisi. 2012; 26: 171-79.

11. Göker Z, Tural-Hesapçıŏlu S, Sarp KS, et all. KTÜ Tıp Fakültesi çocuk-ergen ruh sağlığı ve hastalıkları polikliniğine son iki yılda başvuran adli olguların değerlendirilmesi. Adli Tip Dergisi. 2006; 20: 1-5.

12. Tisak MS, Tisak J, Baker ER, et all. Relations among victimization, witnessing, and perpetration of aggression: impact of gender among youth offenders. J Interpers Violence. 2016; 25: 1-26.

13. Hopkins T, Clegg J, Stackhouse J. Young offenders' perspectives Disord 2016; 51: 95-109.

14. Snowling MJ, Adams JW, Bowyer-Crane C, et all. Levels of literacy among juvenile offenders: the incidence of specific reading difficulties. Crim Behav Ment Health. 2000; 10: 229-41.

15. Church WT, Tomek S, Bolland KAY, et all. A longitudinal examination of predictors of delinquency: an analysis of data from the mobile youth survey. Child Youth Serv Rev. 2012; 34: 2400-408.

16. Oldehinkel AJ, Hartman CA, De Winter AF, et all. Temperament profiles associated with internalizing and externalizing problems in preadolescence. Dev Psychopathol. 2004; 16: 421-40.

17. Loeber R, Pardini D. Neurobiology and the development of violence: common assumptions and controversies. Phil Trans R Soc. 2008; 363: 2491-503.
18. Barkley RA, Fischer M, Smallish L, et all. Young adult follow-up of hyperactive children: antisocial activities and drug use. J Child Psychol Psychiatry. 2004; 45: 195211.

19. Farrington DP. Predictors, causes and correlates of male youth violence. M Tonry, M Moore (Eds.), Youth Violence, Chicago: University of Chicago Press 1998, p.421-75.

20. Schubert CA, Mulvey EP, Glasheen C. Influence of mental health and substance use problems and criminogenic risk on outcomes in serious juvenile offenders. J Am Acad Child Adolesc Psychiatry. 2011; 50: 925-37.

21. Vermeiren R, Colins OF, Popma A, et all. Forensic child, adolescent and transitional psychiatry. Tijdschr Psychiatr. 2015; 57: 881-5.

22. Beaver KM, Shutt JE, Boutwell BB, et all. Genetic and environmental influences on levels of self-control and delinquent peer affiliation: results from a longitudinal sample of adolescent twins. Crim Justice Behav. 2009; 36: 41-60.

23. Schraiber LB, D'Oliveira AF, Couto MT. Violence and health: recent scientific studies. Rev Saude Publica. 2006; 40: 112-20.

24. Kızmaz Z. Öğrenim düzeyi ve suç: suç okul ilişkisi üzerine sosyolojik bir araștırma. Firat Üniversitesi Sosyal Bilimler Dergisi. 2004; 14: 291-319.

25. Nasıroğlu S, Semerci B. Mental problems and sociodemographic characteristics in children driven to committing crimes and the preparation of forensic reports. Psychiatry and Clinical Psychopharmacology. 2017; 27: 132-38.

26. Güler G, Yenilmez Ç, Balcı YG, et all. Çocuk Suçluluğunda Sosyodemografik Özellikler. Klinik Adli Tip. 2001; 1: 69-80.

27. Kurtuluş A, Salman N, Günbet G, et all. Denizli ilinde 12-15 yaş arasındaki suça sürüklenen çocukların sosyodemografik özellikleri. Pamukkale Tıp Dergisi. 2009; 2: 8-14.

28. Hawkins, J. David Herrenkohl, Todd Farrington, et all. A review of predictors of youth violence. 1998. 